Louisiana State University

LSU Digital Commons

Faculty Publications

Department of Chemistry

$2-1-2019$

\title{
Surface Coupling of Octaethylporphyrin with Silicon Tetrachloride
}

Jayne C. Garno

Louisiana State Univ, Dept Chem, jgarno@lsu.edu

Phillip C. Chambers

Louisiana State Univ, Dept Chem

Neepa M. K. Kuruppu Arachchige

Louisiana State Univ, Dept Chem

Ashley M. Taylor

Louisiana State Univ, Dept Chem

Follow this and additional works at: https://digitalcommons.Isu.edu/chemistry_pubs

Part of the Chemistry Commons

\section{Recommended Citation}

Garno, Jayne C.; Chambers, Phillip C.; Arachchige, Neepa M. K. Kuruppu; and Taylor, Ashley M., "Surface Coupling of Octaethylporphyrin with Silicon Tetrachloride" (2019). Faculty Publications. 26.

https://digitalcommons.Isu.edu/chemistry_pubs/26

This Article is brought to you for free and open access by the Department of Chemistry at LSU Digital Commons. It has been accepted for inclusion in Faculty Publications by an authorized administrator of LSU Digital Commons. For more information, please contact gcoste1@lsu.edu. 


\title{
Surface Coupling of Octaethylporphyrin with Silicon Tetrachloride
}

\author{
Phillip C. Chambers, Neepa M. K. Kuruppu Arachchige, Ashley M. Taylor, and Jayne C. Garno*(0) \\ Department of Chemistry, Louisiana State University, 232 Choppin Hall, Baton Rouge, Louisiana 70803, United States
}

\section{Supporting Information}

ABSTRACT: The surface assembly of 2,3,7,8,12,13,17,18octaethylporphyrin (OEP) using silicon tetrachloride as a coupling agent was investigated using atomic force microscopy (AFM). Nanopatterned films of Si-OEP were prepared by protocols of colloidal lithography to evaluate the morphology, thickness, and molecular orientation for samples prepared on $\mathrm{Si}(111)$. The natural self-stacking of porphyrins can pose a challenge for molecular patterning. When making films on
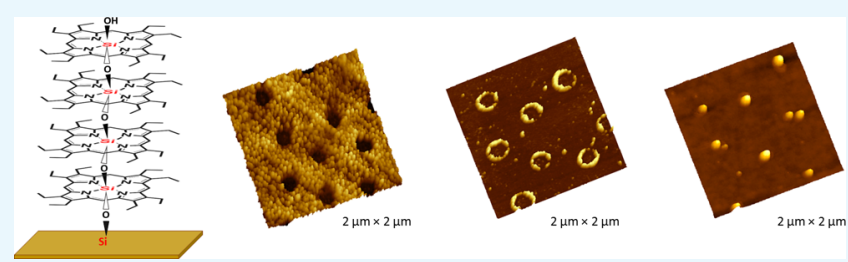
surfaces, porphyrins will self-associate to form co-planar configurations of random stacks of molecules. There is a tendency for the flat molecules to orient spontaneously in a side-on arrangement that is mediated by physisorption to the substrate as well as by $\pi-\pi$ interactions between macrocycles to form a layered arrangement of packed molecules, analogous to a stack of coins. When silicon tetrachloride is introduced to the reaction vessel, the coupling between the surface and porphyrins is mediated through covalent $\mathrm{Si}-\mathrm{O}$ bonding. For these studies, surface structures of $\mathrm{Si}-\mathrm{OEP}$ were formed that are connected with a $\mathrm{Si}-\mathrm{O}-$ Si motif to a silicon atom coordinated to the center of the porphyrin macrocycles. Protocols of colloidal lithography were used as a tool to prepare surface structures and films of Si-OEP to facilitate surface characterizations. Conceptually, by arranging the macrocycles of porphyrins with defined orientation, local AFM surface measurements can be enabled to help address mechanistic questions about how molecules self-assemble and bind to substrates.

\section{INTRODUCTION}

Porphyrins are excellent materials for molecular electronics, due to their diverse structural motifs and associated electrical, optical, and chemical properties and thermal stability. ${ }^{1-6}$ The rigid planar structures and $\pi$-conjugated macrocycles of porphyrins inherently convey stability and robust electrical characteristics. Porphyrins have a macrocyclic tetrapyrrole structure, which may be functionalized with various substituents. ${ }^{7}$ Modifications of the macrocycle, peripheral groups, or bound metal ions can generate a range of electrical and photoelectrical properties. At a basic level, electronic properties of porphyrins are controlled by the degree of $\pi$ delocalization of the conjugated rings. ${ }^{9}$ Porphyrins can be organized into supramolecular arrays, aggregates, and crystals with diverse functions. The diverse architectures of porphyrins have been used for applications such as gas sensors, ${ }^{10,11}$ phototherapeutics, ${ }^{12,13}$ photovoltaic cells, ${ }^{14-17}$ photocatalysis, ${ }^{18,19}$ organic light-emitting diodes, ${ }^{20-23}$ molecular wires, ${ }^{24,25}$ and as components for molecular-based electronic devices. ${ }^{26-30}$

The orientation of porphyrins on surfaces is determined by factors such as the nature of the peripheral substituents and their position on the macrocycle. ${ }^{31,32}$ When preparing surface films, the planar macrocycles of porphyrins spontaneously selfassociate to form stacked structures. This natural capability of self-stacking has been a hurdle for developing processes for molecular patterning, since porphyrins do not form chemisorbed or covalent bonds to surfaces unless a peripheral group is added to the macrocycle to facilitate bonding. Due to the structural nature of tetrapyrrole molecules of porphyrins, the supramolecular organization of nanomaterials and films is driven by forces such as metal-ligand bonds, noncovalent ionic bonds, hydrogen bonding, $\pi-\pi$ interactions, electrostatic and other intermolecular forces including van der Waals forces. ${ }^{33-35}$ There is a tendency for the flat molecules to orient in a co-planar arrangement that is mediated by physisorption to the substrate as well as by electrostatic interactions between macrocycles to form layers of packed molecules in a co-facial arrangement, analogous to a stack of coins.

There is considerable precedent for studies of the synthesis, structures, and properties of porphyrins, and our studies build on such information. Several synthetic approaches have been reported for binding porphyrins to surfaces by designing peripheral groups to facilitate surface self-assembly, as a strategy to enable stronger bonding between the molecules and substrate. By incorporating thiols in peripheral groups of the molecular design, porphyrins can be linked to metal surfaces by chemisorption. ${ }^{36-41}$ A silicon substrate was functionalized with 3-aminopropyl trimethoxysilane (APTMS) to link 5,10,15,20tetrakis-(4-aminophenyl)porphyrin to surface amines using a urea coupling reaction with 1,4 -phenylene diisocyanate. ${ }^{42}$ Zinc and iron porphyrins were attached to silicon substrates functionalized with APTMS by forming an amide bond between the conjugated macrocycle and surface amino groups that were activated by carboxydiimidazole. ${ }^{43}$ The nitrogen of pyridyl moieties was linked to chloro groups of chloromethyl-

Received: November 16, 2018

Accepted: January 18, 2019

Published: February 4, 2019 

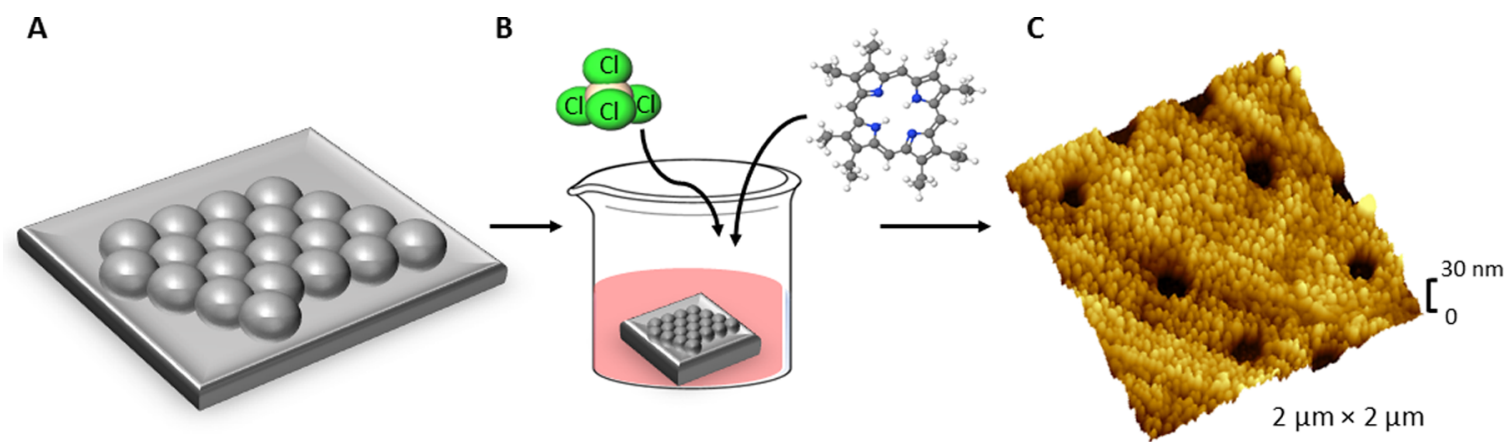

Figure 1. Basic steps for generating nanoholes within a film of Si-OEP using colloidal lithography. (A) An aqueous solution of silica spheres was deposited on a clean $\mathrm{Si}(111)$ substrate and dried. (B) The surface with the particle mask was immersed in a solution of $\mathrm{OEP}_{\text {and }} \mathrm{SiCl}_{4}$ in chloroform for a one-pot reaction. (C) The sample was rinsed with sonication to remove the particle mask to generate nanoholes of uncovered substrate within an OEP film.

phenylsilane to attach tetrapyridyl porphyrin (TPyP) to functionalized $\mathrm{Si}(100)$ substrates. $^{44}$ Cobalt tetraphenyl porphyrins were functionalized with peripheral groups of amines for binding to gold substrates, as reported by Lokesh et al. ${ }^{45}$ As a strategy to covalently bind porphyrin to surfaces of $\mathrm{Si}(100)$ and quartz substrates, multilayer thin films were prepared with TPyP by coating the surface with [ $p$-(chloromethyl)phenyl] trichlorosilane as a coupling layer and then assembling sequential layers with linkers connected to pyridyl groups of the porphyrin ring. ${ }^{46,47}$ Copper(I)-catalyzed azide-alkyne cycloaddition reactivity, commonly referred to as "click" chemistry, has also been used for binding porphyrins to surfaces. ${ }^{48,49}$

In previous reports, nanostructures of silicon complexes of porphyrins and phthalocyanines were successfully prepared using silane coupling to form covalently bound structures on surfaces of silicon, glass, and indium tin oxide (ITO).$^{50-52}$ The silicon atom is bound tightly to the centers of the porphyrin rings by four nitrogens of the conjugated rings. Porphyrins with a nonmetal element such as silicon have two chlorides connected at opposite faces of the macrocycles that facilitate reactions for binding to a surface as well as to form covalent bonds to additional molecules. The synthesis and characterization of several hexacoordinate silicon porphyrins have been reported, including octaethylporphyrin, ${ }^{35}$ tetraphenylporphyrin, ${ }^{3-55}$ tetra-p-tolylporphyrin, and tetrakis $(p$ (trifluoromethyl)phenyl)porphyrin. ${ }^{56}$ One-dimensional polymer wires of Si-porphyrin were prepared on glass and ITO substrates using a silane coupling strategy by Kanaizuka et al. in which a central $\mathrm{Si}$ atom was bound to the center of the porphyrin macrocycle. ${ }^{50}$

Protocols of colloidal lithography employ a surface mask of latex or silica spheres and have been applied for patterning materials such as polymers, ${ }^{57,58}$ proteins, ${ }^{59-65}$ rare-earth nanomaterials, ${ }^{66,67}$ nanoparticles, ${ }^{68,69}$ metals, ${ }^{70-76}$ organosilanes, ${ }^{7-80}$ and organothiols. ${ }^{81}$ We are developing protocols using colloidal lithography to prepare surface films and nanostructures with porphyrins that are covalently bound to silicon substrates. The approach is based on reactions with silicon tetrachloride $\left(\mathrm{SiCl}_{4}\right)$ to form skewered molecules that are centrally interconnected by covalent $\mathrm{Si}-\mathrm{O}$ bonds. Using a "one-pot" reaction with $\mathrm{SiCl}_{4}$, porphyrins are linked to surfaces by $\mathrm{Si}-\mathrm{O}$ bridges directly to a central $\mathrm{Si}$ atom inserted within the macrocycle. Likewise, the macrocycles of porphyrins can be linked together by hydrolysis and condensation steps to form chains with $\mathrm{Si}-\mathrm{O}-\mathrm{Si}$ bridges between the macrocycles. This strategy provides capabilities for controlling the configuration of the macrocycles in a co-facial orientation with covalent bonds. The surface assemblies have been referred to as a "shish kebob" arrangement in which molecules are skewered together by $\mathrm{Si}-\mathrm{O}-\mathrm{Si}$ bridges. ${ }^{82}$ Bonds of $\mathrm{Si}-\mathrm{O}$ are suitable for forming connections to substrates such as silicon wafers, glass, mica, and metal oxides. One may predict that the covalent nature of $\mathrm{Si}-\mathrm{O}-\mathrm{Si}$ substrate linkages will impart stable, robust, and novel electronic and photonic properties depending on the design of the macrocycles. The chemical nature of surface linkages is a critical variable for designing heterojunctions in configurations for molecular electronics.

Herein, we present results for linking porphyrins with $\mathrm{Si}-$ $\mathrm{O}-\mathrm{Si}$ skewers to $\mathrm{Si}(111)$ using $2,3,7,8,12,13,17,18$-octaethylporphyrin (OEP), which is a free-base porphyrin that has eight ethyl groups at pyrrole positions of the macrocycle. Nanopatterning protocols were implemented to facilitate the preparation of well-defined interfaces with nanometer-level control of the spacing and composition of patterned elements. Colloidal lithography with silica spheres provides a practical approach to pattern molecules by masking discrete areas of the surface from molecular deposition. When the mask is removed, bare areas of the substrate are exposed that had been protected by the mask of spheres. The nanostructured films contain nanoholes, which provide an in situ reference for measuring film thickness and also adventitiously furnish landmarks to enable side-by-side comparisons of surface morphology using studies with atomic force microscopy (AFM) (e.g., substrate vs film).

\section{RESULTS AND DISCUSSION}

Three types of surface platforms were prepared using protocols of colloidal lithography to evaluate the morphology and thickness of Si-OEP nanostructures grown on $\mathrm{Si}(111)$ surfaces. First, a film of Si-OEP was prepared that contained nanoholes of an uncovered substrate that had been protected by a surface mask of silica spheres. After the mask was removed, the local areas of $\mathrm{Si}(111)$ within nanoholes furnished a baseline for measuring the thickness of the film which surrounded the nanoholes. In the second nanopatterning strategy, the drying conditions of the masked substrate were altered to generate ring-shaped nanostructures. The third strategy for preparing samples was to make patterns of Si-OEP nanodots within a matrix film of octadecyltrichlorosilane (OTS). In the third example, the initial height of the OTS film provided a reference scale for measuring the growth of Si-OEP nanostructures 

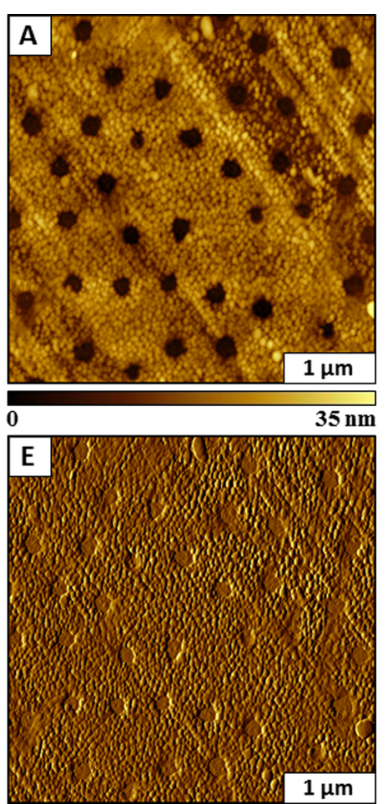
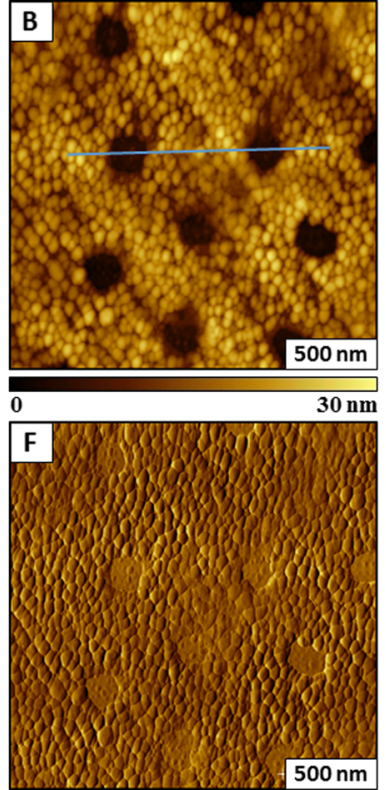
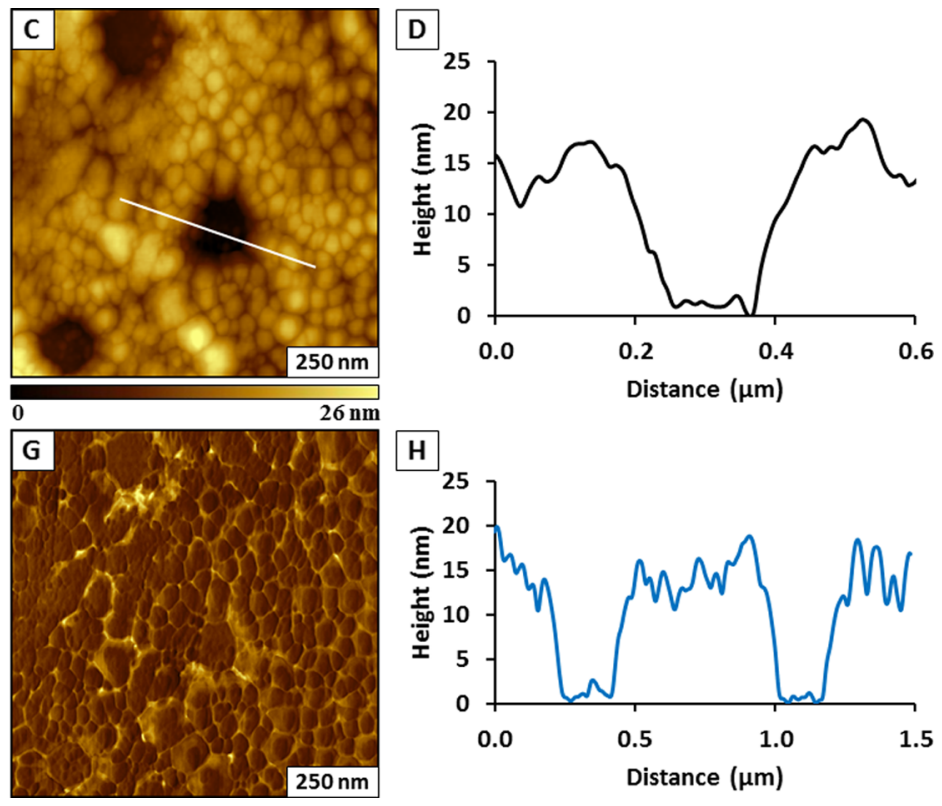

Figure 2. Nanoholes within a film of OEP-silane prepared on $\mathrm{Si}(111)$ after $24 \mathrm{~h}$ immersion, using a surface mask of monodisperse 500 nm $\mathrm{SiO}{ }_{2}$ particles. (A) Topography view of OEP nanoholes $\left(4 \times 4 \mu \mathrm{m}^{2}\right)$; (B) zoom-in topograph $\left(2 \times 2 \mu \mathrm{m}^{2}\right)$; $(\mathrm{C})$ magnified view of three nanoholes $(1 \times$ $\left.1 \mu \mathrm{m}^{2}\right)$; (D) cursor profile for the white line in (C); (E) simultaneously acquired phase image for (A); (F) phase image of (B); (G) phase image of (C); (H) cursor profile for the blue line traced in (B).

within the nanoholes. Molecular-level characterizations with AFM were used to obtain direct views of Si-OEP nanostructures produced by surface self-assembly.

Samples of Nanoholes within a Film of Si-OEP. The steps for fabricating nanoholes within a film of Si-OEP are illustrated in Figure 1. An aqueous solution of monodisperse silica spheres was deposited onto a clean $\mathrm{Si}(111)$ substrate and then dried in air. The spheres spontaneously formed closepacked layers on an atomically flat substrate when dried in ambient conditions to furnish a surface mask for patterning (Figure 1A). The substrate with a mask of spheres was dried in ambient conditions then placed into an oven to temporarily anneal the silica beads to the surface, to prevent the spheres from being washed away during the immersion step. After the drying and annealing step, the masked substrate was then placed into a solution of OEP $(0.5 \mathrm{mM}$ in chloroform containing an excess of $\mathrm{SiCl}_{4}$ ) to initiate coupling of porphyrin and silane (Figure 1B). In the final step, the mask of silica spheres was removed by sonication and rinsing to generate nanoholes of an uncovered substrate within a matrix film of SiOEP (Figure 1C). The thickness of the film grew taller with longer immersion intervals. Control samples were prepared without using $\mathrm{SiCl}_{4}$ and also for a continuous film prepared without a surface mask; AFM images of the control experiments are provided in Figures S1 and S2, Supporting Information.

An example of the interesting morphology of a nanostructured film of skewered molecules of OEP bound to $\mathrm{Si}(111)$ through $\mathrm{Si}-\mathrm{O}$ bridges is shown in Figure 2, after the mask of colloidal Si spheres was rinsed away from the surface. Areas of the film have a distinctive morphology of individual strands of skewered porphyrins which grow vertically from the surface which are not interconnected. The sample has a hexagonal arrangement of circular dark holes surrounded by a film of Si-OEP. Microscopic scratches formed by the polishing of silicon wafers used as substrates appear as diagonal grooves which are attributable to the roughness of the underlying substrate. In this example, the nanoholes were generated using a surface mask of monodisperse $500 \mathrm{~nm}$ silica spheres prepared by drying an aqueous suspension of colloidal silica in ambient conditions, followed by a brief annealing step ( $3 \mathrm{~h})$. After drying, water persists throughout the sample in areas surrounding and between silica spheres of the surface mask. The masked substrate was then cooled and immersed in a solution of OEP and $\mathrm{SiCl}_{4}$ for $24 \mathrm{~h}$. The bright areas are regions of Si-OEP, and the darker areas are the holes where the particle mask was removed (Figure 2A). The successive zoomin views (Figure 2B,C) disclose an interesting topology, the areas of Si-OEP film are punctuated with small disks of the macrocycles. The regular sizes and shapes of the disks suggest a mostly co-planar orientation of columns of flat Si-OEP molecules that do not interconnect in lateral directions. The location, size, and arrangement of the nanoholes are also resolved in the simultaneously acquired phase images (Figure $2 \mathrm{E}-\mathrm{G})$. There are 37 nanoholes within the $4 \times 4 \mu \mathrm{m}^{2}$ frame, which have fairly regular sizes and shapes indicating the sites where silica spheres were removed. The spacing between the nanoholes is $\sim 500 \mathrm{~nm}$, which is derived from the geometry and arrangement of the particles of the surface mask. Within the nanoholes are exposed sites of substrate that were uncovered when the silica spheres were rinsed away. Example line profiles traced across the nanoholes are shown in Figure $2 \mathrm{D}, \mathrm{H}$. The average depth of the nanoholes measured $17 \pm 4$ $\mathrm{nm}$ referencing the uncovered holes as a baseline for cursor measurements. The error term is an estimate of the background roughness of the line profiles. The surface coverage measured $\sim 94 \%$ for the film of Si-OEP shown in Figure 2, the remaining areas are circles of exposed substrate.

The widths of the Si-OEP disks are larger than would be expected for an individual macrocycle, because the AFM probe is much larger than the surface features. An ultrasharp probe could likely reveal the true lateral dimensions, in future planned experiments. The molecules do not interconnect in lateral $x y$ directions, which is evident by the way the AFM 
probe outlines multiple, discrete circular features of highly regular sizes. The molecular assembly seems to occur only in the vertical direction with planar porphyrins assembling on the top of the macrocycles in a concatenated arrangement. The thickness of the film is not uniform. The values measured from individual cursor profiles across 50 nanoholes ranged from 5 to $24 \mathrm{~nm}$ in depth (the size distribution is included as Figure S3, Supporting Information). The thickness measurements indicate that a multilayered film was formed of 16-75 Si-OEP units, which are interconnected by $\mathrm{Si}-\mathrm{O}-\mathrm{Si}$ linkers, using an estimate of $0.32 \mathrm{~nm}$ for each porphyrin unit of the skewered assemblies. The $0.32 \mathrm{~nm}$ value is based on the theoretical length of $\mathrm{Si}-\mathrm{O}-\mathrm{Si}$ bonds.

The results in Figure 2 were acquired at a time point of $24 \mathrm{~h}$ of substrate immersion. Future planned experiments will address the kinetic details of surface assembly by evaluating changes in sample morphology after shorter reaction intervals.

Evidence that $\mathrm{Si}$ was successfully coordinated to the macrocycles of OEP can be readily detected by observing shifts in Soret and $\mathrm{Q}$ bands using UV/vis spectroscopy. Structural changes of the central atom or pendant substituents on the ring will affect the transition energies profiled in absorbance spectra. The absorption bands in systems of chromophoric porphyrins arise from electronic transitions between the two highest occupied molecular orbitals and two lowest unoccupied molecular orbitals of the aromatic rings of the macrocycle, indicating $\pi-\pi$ transitions. ${ }^{83}$ When $\mathrm{SiCl}_{4}$ was added to a solution of OEP, there is a characteristic redshift for the broad Soret band centered around $400 \mathrm{~nm}$, which can be attributed to changes in molecular geometry when a $\mathrm{Si}$ atom is incorporated within the macrocycle (Figure 3). Differences in spectra for the $\mathrm{Q}$ bands were also detected, see the Supporting Information, Figure S4.

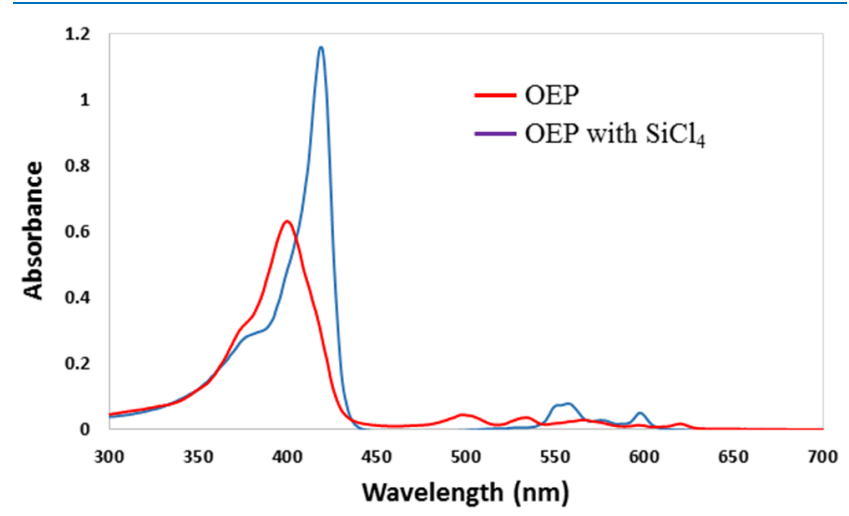

Figure 3. Absorption changes for the UV/vis spectra showing a characteristic redshift of the intense Soret band of OEP after reaction with $\mathrm{SiCl}_{4}$.

Ring-Shaped Nanostructures of Si-OEP. Ring-shaped nanostructures of Si-OEP stacks were produced by altering the conditions for drying the surface mask of silica spheres. Ringshaped morphologies have been reported previously for samples prepared by approaches with colloidal lithography. ${ }^{62,67,78-80,84,85}$ A sample was prepared with oven drying by heating a masked $\mathrm{Si}(111)$ substrate at $150{ }^{\circ} \mathrm{C}$ for $20 \mathrm{~h}$ and then immediately placing the dried sample into a solution of $\mathrm{OEP}$ and $\mathrm{SiCl}_{4}$ in chloroform for $5 \mathrm{~h}$. By heating the substrate for longer intervals (up to $20 \mathrm{~h}$ ), most of the water throughout the surface was driven to evaporate, and only nanoscopic residues of moisture persisted in the water meniscus sites at the base of the particles. The shapes and arrangement of the nanorings are shown in Figure 4 where a few trace adsorbates
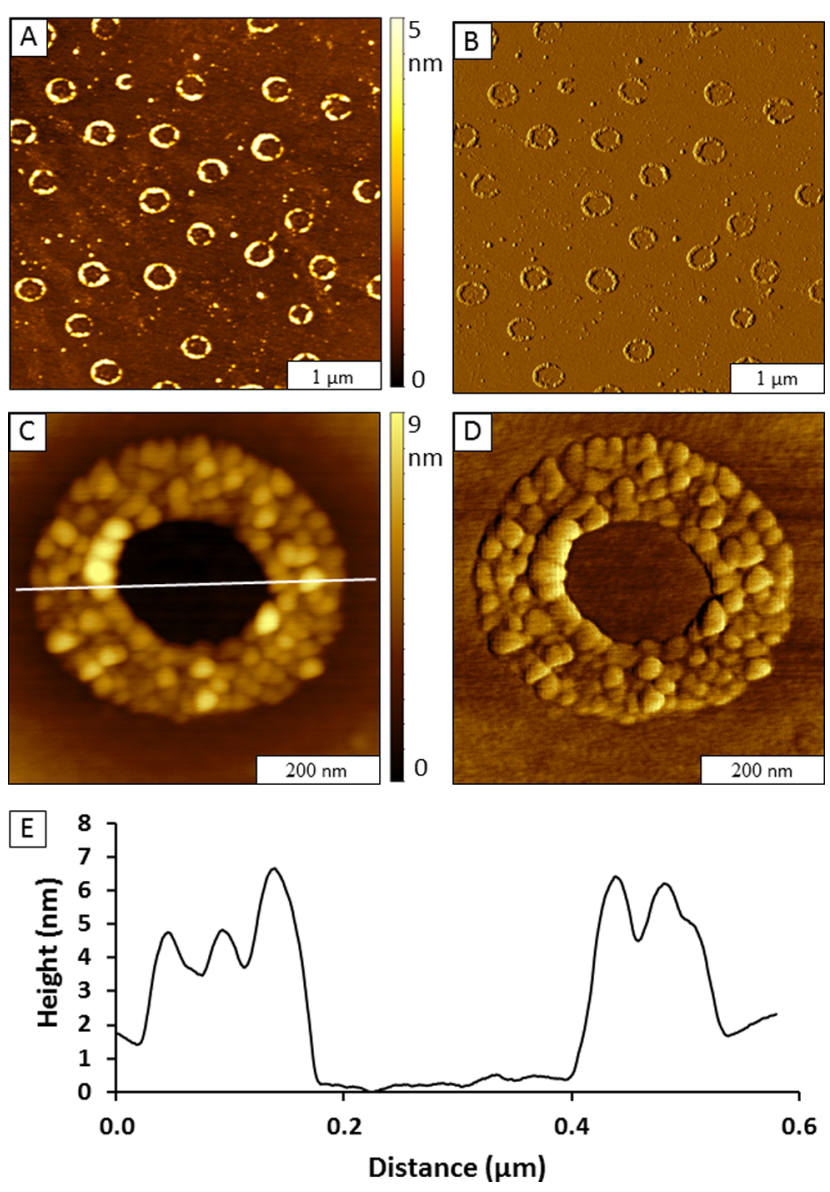

Figure 4. Ring-shaped nanostructures of OEP-silane formed on $\mathrm{Si}(111)$ by changing the drying conditions of the surface mask. The masked substrate was dried in an oven at $150{ }^{\circ} \mathrm{C}$ before immersion in the reaction vessel. (A) Topography view of nanorings, $4 \times 4 \mu \mathrm{m}^{2}$; (B) simultaneously acquired phase image. (C) Zoom-in view of a single Si-OEP nanoring, $600 \times 600 \mathrm{~nm}^{2}$; (D) corresponding phase image. (E) Cursor profile of the line traced in (C). Images were acquired with tapping-mode AFM in air.

of Si-OEP can be detected in areas in between the rings. Molecules of Si-OEP deposited at meniscus sites to form a ring-shaped arrangement surrounding the base of the silica spheres of the surface mask. The beads were completely removed by the steps of rinsing with sonication. The covalent attachment of Si-OEP ensured that the porphyrin film was not removed during solvent rinses, however, the physisorbed silica beads were readily rinsed away to generate a nanostructured organic film, despite the annealing step.

There are about 30 nanorings within the topography image of Figure 4A, which scales to a surface density of $\sim 10^{8}$ nanostructures $/ \mathrm{cm}^{2}$. The simultaneously acquired phase image discloses that the surrounding areas of substrate present different surface chemistry than the areas of the nanorings (Figure 4B). Molecules of Si-OEP did not bind in areas without residual water, the step of heated drying removed water from regions of the substrate in between silica particles to prevent the growth of a continuous film. A close-up view of a single nanoring is shown in Figure 4C. An arrangement of 
A

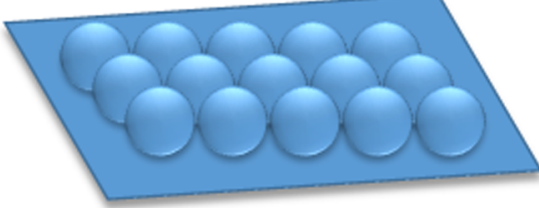

$\mathrm{OH} \mathrm{OH} \mathrm{OH} \mathrm{OH} \mathrm{OH}$
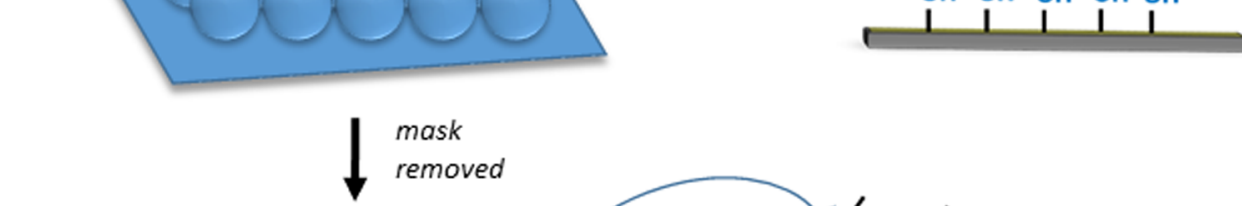

removed

B

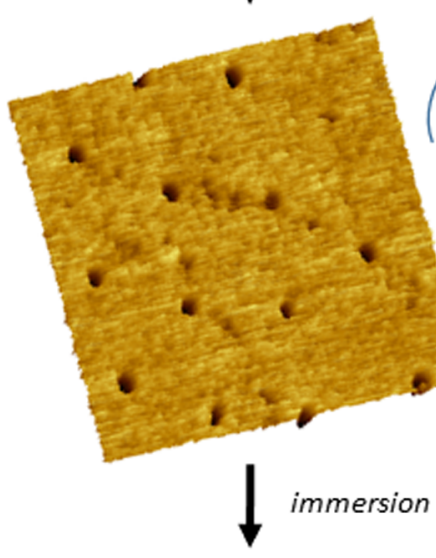

$\mathrm{C}$
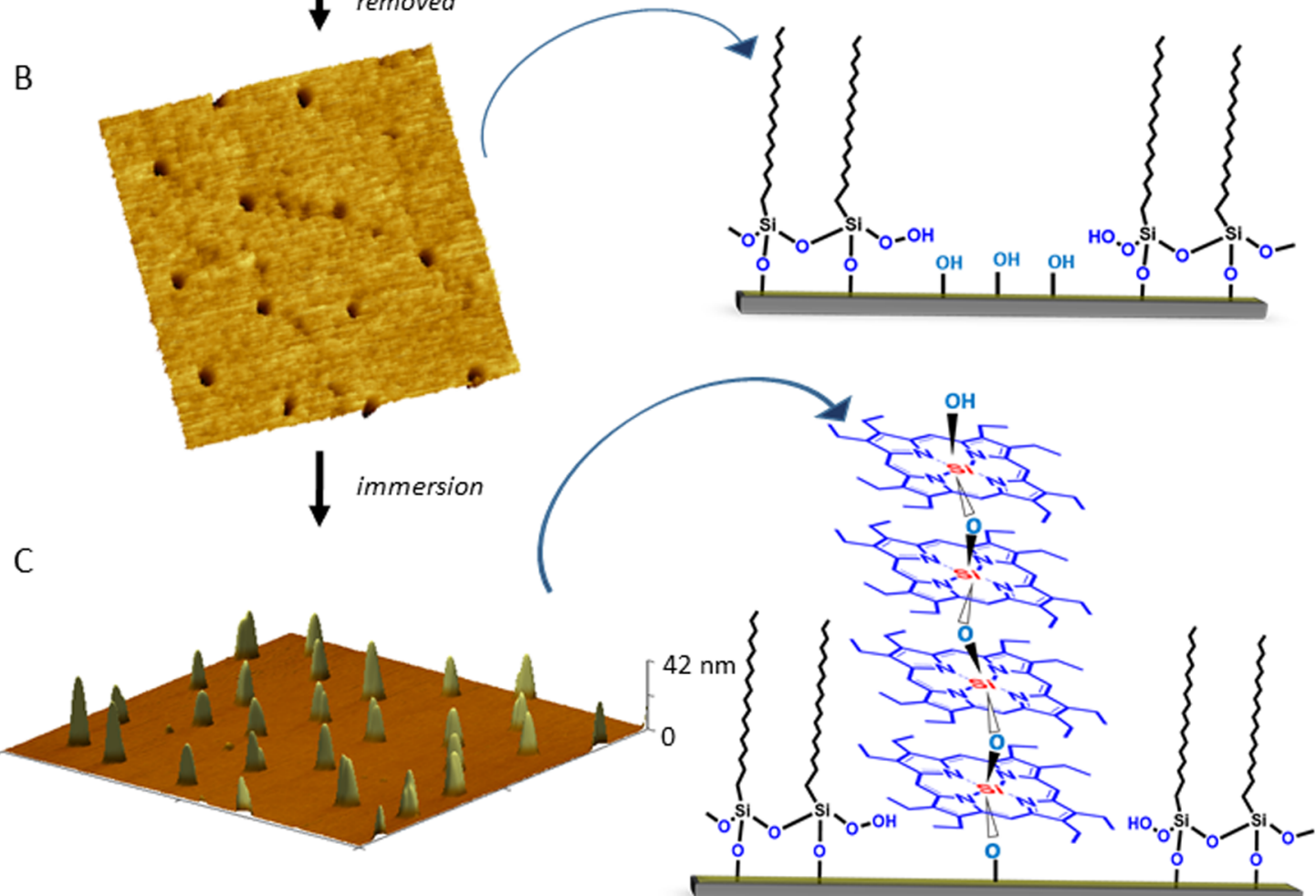

Figure 5. Procedure for preparing OEP nanodots within a resist film of OTS. (A) A particle mask was prepared on Si(111). The colloidal mask protected discrete circular areas from reaction when the sample was immersed in a solution containing OTS. (B) After removing the mask, substrates of nanoholes within an OTS matrix were formed. (C) After a second immersion step in the OEP single-pot reaction, the substrates were removed and dried for AFM characterization to reveal (C) nanodots of OEP grown within the nanoholes.

round disks of Si-OEP assembled to form regular circular shapes surrounding a hole containing uncovered substrate. Fine details of the edges and shapes as well as the surface chemistry of the nanorings are mapped in the corresponding phase image (Figure 4D).

Attachment of Si-OEP takes place at surface sites that follow the shape of the water meniscus which forms at the base of colloidal spheres of a surface mask. The size and shapes of the water meniscus areas are remarkably uniform at the nanoscale. An example cursor measurement across a single ring reveals the multilayer geometry (Figure $4 \mathrm{E}$ ). The average height of the nanorings measured $6.8 \pm 1.5 \mathrm{~nm}(n=50)$. Since there is variability in the heights of the nanorings, both a vertical and horizontal profile of 50 individual rings was acquired to generate a representative measurement. The average value of four measurement points at the top, bottom, left, and right sides of the nanorings was used to gauge the height. With colloidal lithography, the process scales up to tens of millions of surface features of similar geometry, thickness, and composition. Essentially, colloidal lithography provides a means to pattern water on substrates, and molecules of Siporphyrin bind selectively to the locations of the wetted substrate.
Nanodots of Si-OEP within an OTS Matrix. Nanostructures of Si-OEP were fabricated within a methyl-terminated resist layer by localizing the reaction to confined sites of nanoholes within a film of octadecyltrichlorosilane (OTS) that was prepared using an immersion step with colloidal lithography. Nanoholes within a film of methyl-terminated OTS was used to furnish nanoscopic containers for depositing Si-porphyrin. In previous studies, we have successfully used OTS as a generic matrix with colloidal lithography to pattern 4-(chloromethyl)phenyl trichlorosilane, ${ }^{86}$ polymers, ${ }^{57}$ proteins, ${ }^{61,87}$ rare-earth oxide nanoparticles, ${ }^{88}$ as well as freebase and metallated porphyrins. ${ }^{89}$ Methyl-terminated decyltrichlorosilane was used as a resist for patterning OTS by Brownfield et al. ${ }^{79}$ Patterns of $n$-docosane, aspirin, and clarithromycin were produced within a matrix of OTS, as reported by Wang et al. ${ }^{80}$ Beyond colloidal lithography, matrices of OTS have also been used with other nanolithography approaches for patterning organic films to attach carbon nanotubes, ${ }^{90}$ metal wires, ${ }^{91}$ nanoparticles, ${ }^{92,93}$ and proteins. $^{94}$

The steps for spatially selective deposition of Si-OEP into uncovered nanoholes within an OTS film are depicted in Figure 5 . Nanoholes of unprotected $\mathrm{Si}(111)$ were prepared by 
removing the particle mask. The sites of nanoholes were used to direct and confine the deposition and subsequent vertical layer-by-layer assembly of Si-OEP. In the first step (Figure $5 \mathrm{~A}$ ), colloidal lithography was used to generate a template of nanoholes of an uncovered substrate within a thin film of OTS using a surface mask of colloidal spheres. After removing the mask (Figure 5B), the areas that had been protected by the spheres furnish circular sites of uncovered Si substrate, which present hydroxyl groups, surrounded by a passivating layer of methyl-terminated OTS. In the final step, the substrate with nanoholes was placed into the porphyrin and $\mathrm{SiCl}_{4}$ solution for a one-pot coupling reaction. After the reaction, the sample was removed and rinsed successively with chloroform and water for characterization with AFM (Figure 5C).

An example of nanoholes produced by immersing a colloidal mask in a solution of OTS is presented in Figure 6. Most of the areas of the surface are covered with a monolayer film of OTS on $\mathrm{Si}(111)$, however, discrete holes of regular sizes are arranged throughout the sample according to the hexagonal packing of the surface mask (Figure 6A). A magnified view of 12 nanoholes is shown in Figure 6B, disclosing the highly regular shapes of the circular features. The theoretical length of OTS is $2.5 \mathrm{~nm}$ for an upright, fully extended orientation of the hydrocarbon backbone. The depth of the nanoholes for the OTS sample measured $2.3 \pm 0.3 \mathrm{~nm}(n=50)$ as shown with an example cursor profile in Figure 6C, which suggests that the film was fairly densely packed. The nanostructured film of OTS was used as a surface template for directing the deposition of Si-OEP for the experiment shown in Figure 7.

When a sample of nanoholes was submerged in a solution of $\mathrm{Si}$-OEP, the porphyrins did not attach to areas of the sample protected by OTS which present methyl groups. Molecules of Si-OEP assembled on uncovered, bare areas inside the nanoholes to form nanostructures of regular shapes and thickness, shown with representative AFM images in Figure 7. The time point for immersion of this example was $5 \mathrm{~h}$, revealing heights that measure $6 \pm 1 \mathrm{~nm}(n=50)$ above the OTS matrix. In data not shown, immersion for $24 \mathrm{~h}$ formed taller structures measuring $8.7 \pm 1.9 \mathrm{~nm}$ in height. These experiments provide mechanistic clues of a layer-by-layer mode of surface assembly with $\mathrm{Si}$-OEP that produces taller structures as molecules are added over time. Intermolecular $\mathrm{Si}-\mathrm{O}-\mathrm{Si}$ linkages form co-facially on the exposed face of the surfacelinked porphyrins, to interconnect with the central Si atoms of the macrocycles in a skewered arrangement.

There are about 68 nanodots of Si-OEP in the topograph of Figure $7 \mathrm{~A}$, within a $6 \times 6 \mu \mathrm{m}^{2}$ frame. The number of nanopatterns that can be generated is controlled by the diameter of the particles chosen for the colloidal mask, correspondingly more structures are generated when smaller diameter spheres are used for lithography. ${ }^{95,96}$ The nanodots have a hexagonal arrangement, with a periodicity that matches the diameter of the silica spheres $(500 \mathrm{~nm})$ used as a surface mask. Close-up views of the Si-OEP nanodots are presented in Figure 7B,C, revealing a morphology of multiple island aggregates packed within the nanocontainers. The clustered protrusions can also be vaguely resolved in the simultaneously acquired phase images of Figure $7 \mathrm{D}, \mathrm{E}$ as small bumps inside the dark holes. The phase images enable sensitive detection of adsorbates in areas between the nanodots, in this example, no contaminants are observed on areas of the OTS matrix film. An example cursor profile across two nanostructures is shown in Figure 7F, with heights measuring 5.1 and $4.3 \mathrm{~nm}$.
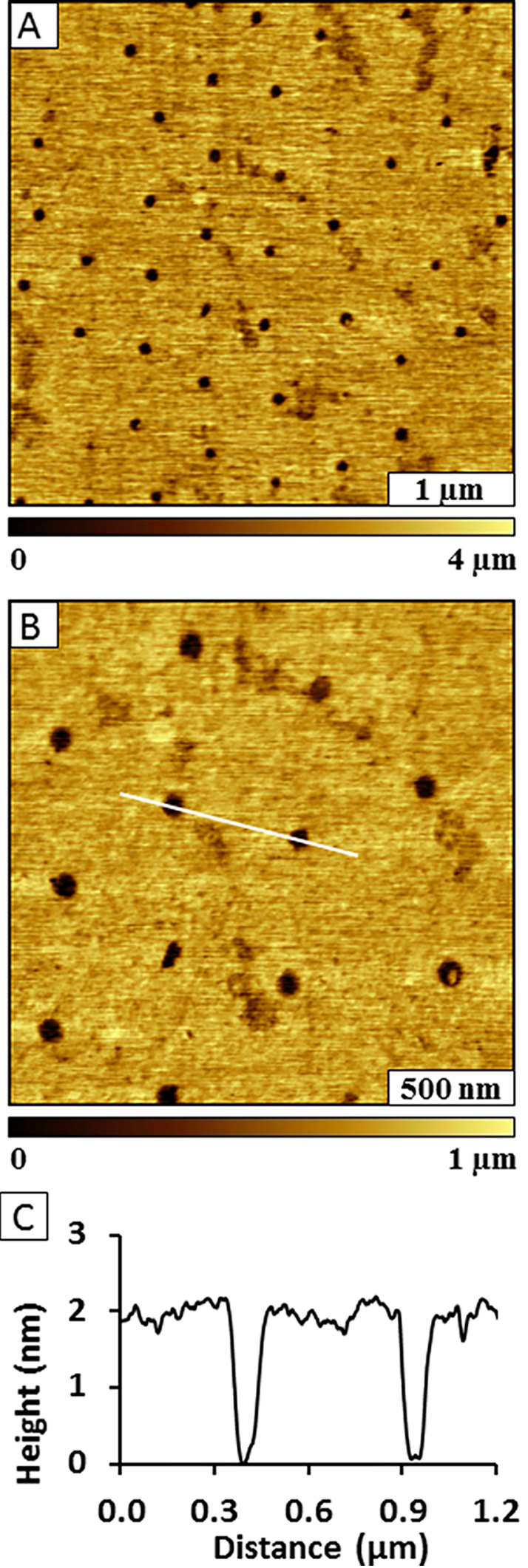

Figure 6. Nanoholes within a film of OTS viewed with topography frames acquired in air using tapping-mode AFM. (A) Topography view $\left(4 \times 4 \mu \mathrm{m}^{2}\right)$; (B) zoom-in view $\left(2 \times 2 \mu \mathrm{m}^{2}\right)$ of nanoholes; (C) cursor profile for the line drawn in (B).

At the nanoscale, there is variability for the heights of the nanodots, shown in the histograms of Figure 8. With an 

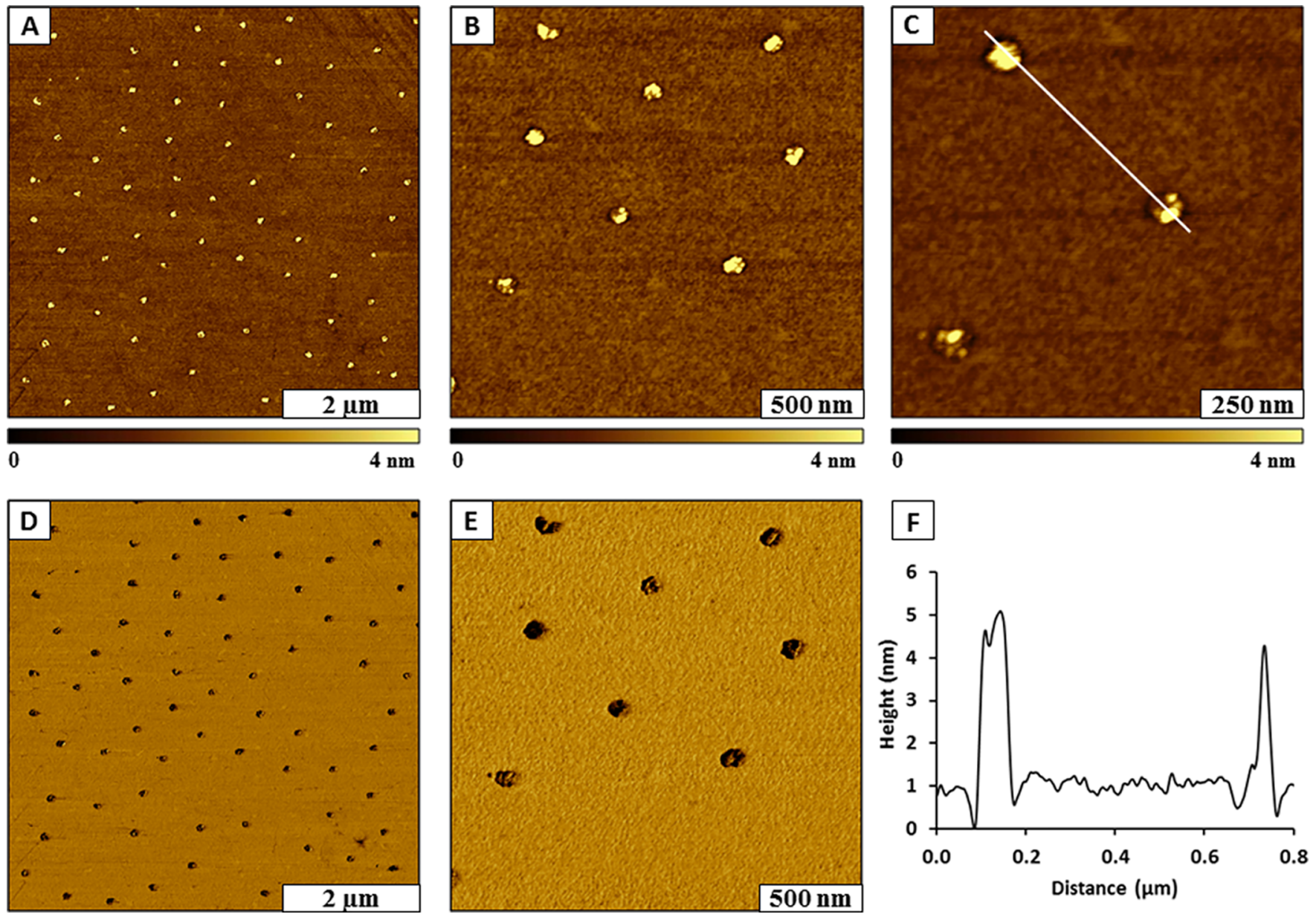

Figure 7. Nanodot patterns of OEP grown within nanoholes within an OTS matrix film. (A) Topography view of OEP nanodots $\left(6 \times 6 \mu \mathrm{m}^{2}\right) ;(B)$ zoom-in view $\left(2 \times 2 \mu \mathrm{m}^{2}\right)$; (C) magnified view $\left(1 \times 1 \mu \mathrm{m}^{2}\right)$; (D) phase image acquired for (A); (E) phase image for (B); (F) cursor profile for the line in $(\mathrm{C})$.
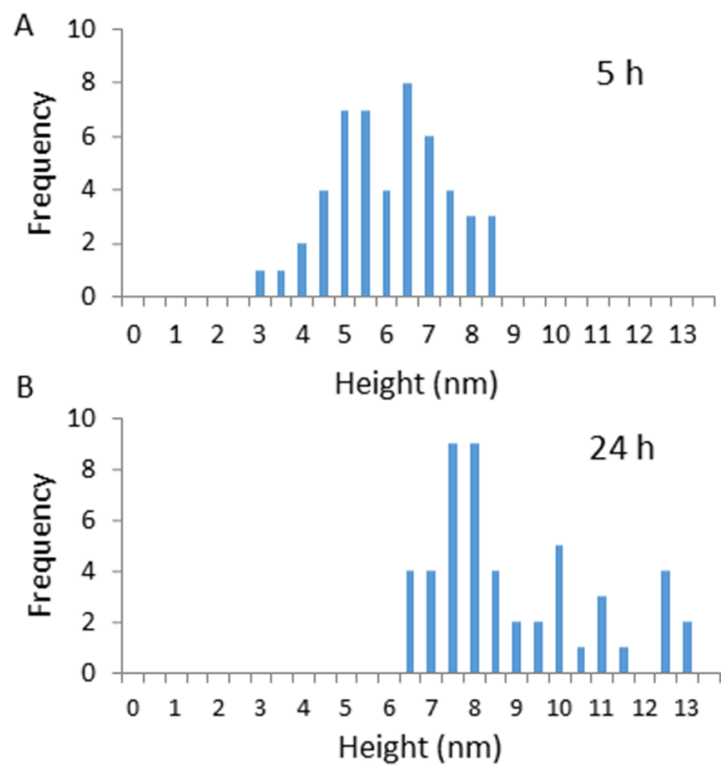

Figure 8. Comparison of height measurements for OEP nanodots derived from cursor profiles (A) after $5 \mathrm{~h}$ immersion; (B) after $24 \mathrm{~h}$ immersion of substrates with nanoholes of OTS/Si(111).

immersion time of $5 \mathrm{~h}$, the heights above the OTS matrix ranged from 3 to $9 \mathrm{~nm}$, with an average value of $5.8 \pm 1.3 \mathrm{~nm}$.
With a longer immersion time of $24 \mathrm{~h}$, the heights ranged from 6 to $13 \mathrm{~nm}$, with an average value of $8.7 \pm 1.9 \mathrm{~nm}$. The mean values of the two data sets ( 5 and $24 \mathrm{~h}$ ) are statistically different, compared using a paired $t$-test at the 99.5 percentile. The variability of the heights of nanodots can be attributed to slight changes in the diameters of the nanoholes which occur naturally from variations of particle sizes of the surface mask as well as surface imperfections.

Role of Water in Surface Binding. Water directs the surface placement of the initial layer of Si-OEP and also has a role in the addition of further molecules to form a skewered multilayer. The particle masks were found to effectively block molecules from depositing underneath spheres at the points of direct contact with the substrate, molecules of Si-OEP were directed to assemble at interstitial sites in between the silica beads or at meniscus sites at the wetted areas of the substrate. Organosilane nanostructures of selected morphologies can be fabricated with colloidal lithography by controlling certain experimental parameters such as concentration, immersion intervals, and the drying conditions for the surface mask. In ambient conditions, a layer of water forms on surfaces; trace amounts of water initiate self-assembly of organosilanes to form a molecularly thin organic film. Through trial and error, we have learned that the nature of the substrate can influence silanization reactions. For example, with the relatively hydrophilic surface of mica, water will spread out to form a 
continuous layer which will correspondingly generate organic films of uniform thickness throughout areas of the sample. However, with hydrophobic substrates such as $\mathrm{Si}(111)$, the nature of the surface directs organosilane assembly according to the arrangement of water deposits. ${ }^{97}$ For colloidal lithography protocols, the amount of water present on the surface can be controlled by altering the drying conditions of the masked substrate before the immersion step. ${ }^{79,98}$

The key differences when comparing the surface morphology of samples of Figures 2 and 4 were the drying conditions of the surface mask used for preparing samples with colloidal lithography and the intervals for immersion in Si-OEP. The process for attaching silanes to substrates requires nanoscopic residues of water on the surface; areas with thicker layers of water will furnish sites for self-polymerization to produce multilayered films. With colloidal lithography, the locations of water on the surface define the reaction sites for attaching $\mathrm{SiCl}_{4}$ and OEP. In essence, the drying step of colloidal lithography is a way to control the shapes and thickness of SiOEP nanostructures. In ambient conditions, we know that macroscopic residues of moisture form on mirrors and glass surfaces to form water films or fog. Intuitively with colloidal lithography, by drying a sample in air under ambient conditions, the entire surface would have a film of water throughout the sample, except at sites protected by the particle mask. Therefore, an ambient drying step produces a film of molecules with nanoholes in areas where the particles of the mask were removed as revealed in the example of Figure 2. However, when using a heated drying step for the particle mask, nanorings were produced in areas where water persisted selectively at the meniscus sites surrounding the base of the silica spheres, as shown in Figure 4. When using silica spheres of smaller diameter, the size of the meniscus is smaller and the corresponding ring nanopatterns are smaller in size. Thus, colloidal lithography provides a tool for controlling the sites of reactions at the nanoscale as well as providing a way to choose the geometry and spacing between patterns of nanoholes or nanorings.

\section{CONCLUSIONS}

Nanostructured films, nanorings, and nanodots of Si-OEP were patterned through covalent $\mathrm{Si}-\mathrm{O}-\mathrm{Si}$ bonds using a silane coupling reaction combined with colloidal lithography. Molecules were added over time to form multilayers, as demonstrated by measuring the changes in height after increasing the time intervals for immersing silicon substrates from 5 to $24 \mathrm{~h}$. With colloidal lithography, the geometry of nanostructures was affected by the drying step of preparing surface masks, which defines the placement of water residues on the surface. The nanostructures consisted of multiple strands of porphyrin stacks that assembled from the surface through a siloxane backbone attached covalently to the central $\mathrm{Si}$ atom of the macrocycles in a skewered arrangement. The experimental results with Si-OEP provide a basis for developing protocols with other porphyrins and can likely be extended to phthalocyanines which have a macrocycle comprised of four isoindole groups linked by nitrogen atoms. Further directions will be to study the role of substitutions with peripheral groups, (phenyl, methyl, pyridyl, polar, nonpolar, etc.) as well as the effects of symmetry for modification of the macrocycle. Our goals are to correlate nanoscale properties (conductance, photocurrent generation) with designed surface structures of porphyrins in which the coupling between the surface and porphyrins is mediated by stable covalent interactions.

\section{EXPERIMENTAL SECTION}

Materials and Reagents. Precut polished silicon wafers $\mathrm{Si}(111)$ were purchased from Ted Pella, Inc. (Redding, CA). Octadecyltrichlorosilane (OTS) was obtained from Acros Organics, Thermo Fisher Scientific (New Jersey). Silicon tetrachloride and 2,3,7,8,12,13,17,18-octaethylporphyrin (OEP) were obtained from TCI America (Portland, OR). Size-sorted silica spheres $(500 \mathrm{~nm})$ were obtained from Thermo Scientific (Fremont, CA). Chloroform (high-performance liquid chromatography grade) was acquired from Fisher Scientific (Lenexa, KS). Concentrated sulfuric acid (98.0\%) (J.T. Baker, Fisher Scientific) and hydrogen peroxide (30\%) (British Drug Houses, VWR) were used to prepare piranha solution. Ethanol was purchased from Deacon Labs (Prussia, PA) and used as received. Anhydrous toluene was purchased from Merck Millipore (Billerica, MA).

UV/Vis Spectroscopy. Absorbance spectra were acquired with a Cary model $50 \mathrm{UV} /$ vis spectrophotometer from Varian Instruments (Santa Clara, CA).

Atomic Force Microscopy. Samples were characterized using a model 5500 atomic force microscope (Keysight Technologies, Santa Rosa, CA). Results were acquired using a tapping-mode AFM. Unless otherwise specified, the error values for cursor measurements indicate the standard deviation of multiple line profiles. Nonconductive silicon nitride tips were used for AFM studies. Tapping-mode images were acquired using tips with an average spring constant between 10 and $130 \mathrm{~N} / \mathrm{m}$ and resonance frequencies ranging from 272 to $464 \mathrm{kHz}$ (Nanosensors, Neuchatel, Switzerland). Digital images were processed using Gwyddion software, which is supported by the Czech Metrology Institute. ${ }^{99}$

Preparation of Nanostructured Films of Si-OEP. An immersion procedure was used to generate a thin film of SiOEP on $\mathrm{Si}(111)$. Precut polished silicon wafers (Virginia Semiconductor, Frederickburg, VA) were rinsed with ultrapure water and then immersed in piranha solution for $1.5 \mathrm{~h}$ to remove surface contaminants. Piranha solution is a mixture of hydrogen peroxide and sulfuric acid with a (v/v) ratio of $1: 3$. Caution: piranha solution is highly corrosive and should be handled with great care. Next, the substrates were removed and rinsed with water. Thin films were made by adding $2.9 \mu \mathrm{L}$ of neat $\mathrm{SiCl}_{4}$ to $5 \mathrm{~mL}$ of a solution of OEP $(0.5 \mathrm{mM})$ in chloroform. Silicon substrates were placed in the OEP solution to react for $5 \mathrm{~h}$. The samples were then removed from the solution, rinsed with ethanol and ultrapure water, and sonicated in chloroform. Next, the samples were dried under nitrogen and subsequently characterized with AFM.

Preparation of Nanopatterns. An aqueous suspension of silica spheres was prepared by successive cycles of centrifugation to remove contaminants. After centrifuging an aqueous solution of $500 \mathrm{~nm}$ silica spheres $(0.2 \mathrm{~mL})$, the supernatant was decanted and replaced with deionized water $(0.2 \mathrm{~mL})$. The spheres of the pellet were resuspended using vortex mixing. The process was repeated three times to ensure complete removal of contaminants. Next, an aliquot $(10 \mu \mathrm{L})$ of the suspension was deposited onto a clean piece of silicon and dried in air. The samples were then placed into an oven at 150 ${ }^{\circ} \mathrm{C}$ for time intervals ranging from 3 to $20 \mathrm{~h}$.

To prepare patterns of nanoholes within a film of OTS, the substrate with a mask of silica spheres was immersed in a 
solution of OTS $(0.1 \%$ in anhydrous toluene) for $5 \mathrm{~h}$. The sample was then removed from the solution and further rinsed with ethanol and deionized water. Next, the surface mask of spheres was removed by sonication in ethanol and water. Nanopatterns of OEP were prepared by immersing the sample with nanoholes within an OTS matrix into a solution containing OEP and $\mathrm{SiCl}_{4}$ in chloroform for 5 or $24 \mathrm{~h}$. The samples were removed and rinsed in ethanol and water followed by sonication in chloroform, then characterized with AFM.

\section{ASSOCIATED CONTENT}

\section{S Supporting Information}

The Supporting Information is available free of charge on the ACS Publications website at DOI: 10.1021/acsomega.8b03204.

Images of an OEP sample prepared without using $\mathrm{SiCl}_{4}$ (Figure S1); film of Si-OEP prepared without a surface mask (Figure S2); film thickness measurements after 24 $\mathrm{h}$ immersion in Si-OEP (Figure S3); absorption spectra of the changes of $\mathrm{Q}$ bands for OEP and Si-OEP (Figure S4) (PDF)

\section{AUTHOR INFORMATION}

\section{Corresponding Author}

*E-mail: jgarno@lsu.edu. Phone: 225-578-8942.

\section{ORCID}

Jayne C. Garno: 0000-0003-3446-1780

Notes

The authors declare no competing financial interest.

\section{ACKNOWLEDGMENTS}

The authors gratefully acknowledge financial support from the Louisiana Board of Regents Support Fund Traditional Enhancement Program (LEQSF(2014-16)-ENH-TR-03).

\section{REFERENCES}

(1) Liu, C.-Y.; Pan, H.-L.; Fox, M. A.; Bard, A. J. High-Density Nanosecond Charge Trapping in Thin-Films of the Photoconductor ZnODEP. Science 1993, 261, 897-899.

(2) Fox, M. A. Fundamentals in the Design of Molecular Electronic Devices: Long-Range Charge Carrier Transport and Electronic Coupling. Acc. Chem. Res. 1999, 32, 201-207.

(3) Adams, D. M.; Kerimo, J.; Liu, C.-Y.; Bard, A. J.; Barbara, P. F. Electric field modulated near-field photo-luminescence of organic thin films. J. Phys. Chem. B 2000, 104, 6728-6736.

(4) Kimura, M.; Saito, Y.; Ohta, K.; Hanabusa, K.; Shirai, H.; Kobayashi, N. Self-Organization of Supramolecular Complex Composed of Rigid Dendritic Porphyrin and Fullerene. J. Am. Chem. Soc. 2002, 124, 5274-5275.

(5) Burrows, H. D.; Gonsalves, A. M. R.; Leitao, M. L. P.; Miguel, M. D. G.; Pereira, M. M. Phase transitions and self-assembly in mesotetrakis(undecyl)porphyrin. Supramol. Sci. 1997, 4, 241-246.

(6) Tsuda, A.; Osuka, A. Fully Conjugated Porphyrin Tapes with Electronic Absorption Bands That Reach into Infrared. Science 2001, 293, 79-82.

(7) Suslick, K. S.; Rakow, N. A.; Kosal, M. E.; Chou, J.-H. The materials chemistry of porphyrins and metalloporphyrins. J. Porphyrins Phthalocyanines 2000, 4, 407-413.

(8) Guo, X. L.; Dong, Z. C.; Trifonov, A. S.; Miki, K.; Kimura, K.; Mashiko, S. STM-induced molecular fluorescence. Appl. Phys. A: Mater. Sci. Process. 2005, 81, 367-370.

(9) Reimers, J. R.; Hall, L. E.; Crossley, M. J.; Hush, N. S. Rigid fused oligoporphyrins as potential versatile molecular wires. 2. B3LYP and SCF calculated geometric and electronic properties of 98 oligoporphyrin and related molecules. J. Phys. Chem. A 1999, 103, $4385-4397$

(10) Filippini, D.; Alimelli, A.; Natale, C. D.; Paolesse, R.; D’Amico, A.; Lundstrom, I. Chemical Sensing with Familiar Devices. Angew. Chem., Int. Ed. 2006, 45, 3800-3803.

(11) Malinski, T.; Taha, Z. Nitric-Oxide Release from a Single Cell Measured In Situ by a Porphyrinic-Based Microsensor. Nature 1992, 358, 676-678.

(12) Lo, P.-C.; Huang, J.-D.; Cheng, D. Y. Y.; Chan, E. Y. M.; Fong, W.-P.; Ko, W.-H.; Ng, D. K. P. New amphiphilic silicon(IV) phthalocyanines as efficient photosensitizers for photodynamic therapy: Synthesis, photophysical properties, and in vitro photodynamic activities. Chem. - Eur. J. 2004, 10, 4831-4838.

(13) Galstyan, A.; Kauscher, U.; Block, D.; Ravoo, B. J.; Strassert, C. A. Silicon(IV) phthalocyanine-decorated cyclodextrin vesicles as a self-assembled phototherapeutic agent against MRSA. ACS Appl. Mater. Interfaces 2016, 8, 12631-12637.

(14) Zysman-Colman, E.; Ghosh, S. S.; Xie, G.; Varghese, S.; Chowdhury, M.; Sharma, N.; Cordes, D. B.; Slawin, A. M. Z.; Samuel, I. D. W. Solution-processable silicon phthalocyanines in electroluminescent and photovoltaic devices. ACS Appl. Mater. Interfaces 2016, 8, 9247-9253.

(15) Marée, C. H. M.; Roosendaal, S. J.; Savenije, T. J.; Schropp, R. E. I.; Schaafsma, T. J.; Habraken, F. H. P. M. Photovoltaic effects in porphyrin polymer films and heterojunctions. J. Appl. Phys. 1996, 80, 3381-3389.

(16) Murata, K.; Ito, S.; Takahashi, K.; Hoffman, B. M. Photocurrent from photocorrosion of aluminum electrode in porphyrin/Al Schottky-barrier cells. Appl. Phys. Lett. 1997, 71, 674-676.

(17) Cai, J.; Chen, H.; Huang, J.; Wang, J.; Tian, D.; Dong, H.; Jiang, L. Controlled self-assembly and photovoltaic characteristics of porphyrin derivatives on a silicon surface at solid-liquid interfaces. Soft matter 2014, 10, 2612-2618.

(18) Chen, Y.; Li, A.; Huang, Z.-H.; Wang, L.-N.; Kang, F. Porphyrin-based nanostructures for photocatalytic applications. Nanomaterials 2016, 6, 51.

(19) Ussia, M.; Bruno, E.; Spina, E.; Vitalini, D.; Pellegrino, G.; Ruffino, F.; Privitera, V.; Carroccio, S. C. Freestanding photocatalytic materials based on 3D graphene and polyporphyrins. Sci. Rep. 2018, 8, No. 5001.

(20) Harima, Y.; Okazaki, H.; Kunugi, Y.; Yamashita, K.; Ishii, H.; Seki, K. Formation of Schottky barriers at interfaces between metals and molecular semiconductors of $\mathrm{p}$ - and n- type conductances. Appl. Phys. Lett. 1996, 69, 1059-1061.

(21) Chowdhury, A.; Chowdhury, J.; Pal, P.; Pal, A. J. Light-emitting diodes from molecularly thin porphyrin derivative: Effect of molecular packing. Solid State Commun. 1998, 107, 725-729.

(22) Baldo, M. A.; O’Brien, D. F.; You, Y.; Shoustikov, A.; Sibley, S.; Thompson, M. E.; Forrest, S. R. Highly efficient phosphorescent emission from organic electroluminescent devices. Nature 1998, 395, $151-154$.

(23) Kwong, R. C.; Sibley, S.; Dubovoy, T.; Baldo, M.; Forrest, S. R.; Thompson, M. E. Efficient, saturated red organic light emitting devices based on phosphorescent platinum(II) porphyrins. Chem. Mater. 1999, 11, 3709-3713.

(24) Sendt, K.; Johnston, L. A.; Hough, W. A.; Crossley, M. J.; Hush, N. S.; Reimers, J. R. Switchable Electronic Coupling in Model Oligoporphyrin Molecular Wires Examined through the Measurement and Assignment of Electronic Absorption Spectra. J. Am. Chem. Soc. 2002, 124, 9299-9309.

(25) Robertson, N.; McGowan, C. A. A comparison of potential molecular wires as components for molecular electronics. Chem. Soc Rev. 2003, 32, 96-103.

(26) Jurow, M.; Schuckman, A. E.; Batteas, J. D.; Drain, C. M. Porphyrins as molecular electronic components of functional devices. Coord. Chem. Rev. 2010, 254, 2297-2310.

(27) Roth, K. M.; Dontha, N.; Dabke, R. B.; Gryko, D. T.; Clausen, C.; Lindsey, J. S.; Bocian, D. F.; Kuhr, W. G. Molecular approach 
toward information storage based on the redox properties of porphyrins in self-assembled monolayers. J. Vac. Sci. Technol, B: Microelectron. Nanometer Struct.-Process., Meas., Phenom. 2000, 18, 2359.

(28) Jiao, J.; Anariba, F.; Tiznado, H.; Schmidt, I.; Lindsey, J. S.; Zaera, F.; Bocian, D. F. Stepwise Formation and Characterization of Covalently Linked Multiporphyrin-Imide Architectures on $\mathrm{Si}(100)$. J. Am. Chem. Soc. 2006, 128, 6965-6974.

(29) Roth, K. M.; Liu, Z.; Gryko, D. T.; Clausen, C.; Lindsey, J. S.; Bocian, D. F.; Kuhr, W. G. Charge-Retention Characteristics of SelfAssembled Monolayers of Molecular-Wire-Linked Porphyrins on Gold. In Molecules as Components of Electronic Devices; Lieberman, M., Ed.; Oxford University Press: Washington DC, 2003; Chapter 5.

(30) Liu, C.-Y.; Pan, H. L.; Fox, M. A.; Bard, A. J. Reversible charge trapping/detrapping in a photoconductive insulator of liquid crystal zinc porphyrin. Chem. Mater. 1997, 9, 1422-1429.

(31) Milic, T.; Garno, J. C.; Smeureanu, G.; Batteas, J. D.; Drain, C. M. Organization of Self-Assembled Tetrameric Porphyrin Arrays on Surfaces. Langmuir 2004, 20, 3974-3983.

(32) Garno, J. C.; Xu, C.; Batteas, J. D.; Drain, C. M. Designing Supramolecular Porphyrin Arrays for Surface Assembly and Patterning of Optoelectronic Materials. In Metal-Containing and Metallosupramolecular Polymers and Materials; Schubert, U. S., Newkome, G. R., Manners, I., Eds.; ACS Symposium Series 928; Oxford University Press: Washington, DC, 2005; Chapter 13, pp $168-183$.

(33) Gao, Y.; Zhang, X.; Ma, C.; Li, X.; Jiang, J. Morphologycontrolled self-assembled nanostructures of 5,15-di[4-(5acetylsulfanylpentyloxy)phenyl]porphyrin derivatives. Effect of metal-ligand coordination bonding on tuning the intermolecular interaction. J. Am. Chem. Soc. 2008, 130, 17044-17052.

(34) Ariga, K.; Hill, J. P.; Ji, Q. Layer-by-layer assembly as a versatile bottom-up nanofabrication technique for exploratory research and realistic application. Phys. Chem. Chem. Phys. 2007, 9, 2319-2340.

(35) Kadish, K. M.; Xu, Q. Y.; Barbe, J. M.; Guilard, R. Synthesis and reactivity of sigma.-bonded silicon metalloporphyrins. Spectroscopic characterization and electrochemistry of $(\mathrm{P}) \mathrm{Si}(\mathrm{R}) 2,(\mathrm{P}) \mathrm{Si}(\mathrm{R}) \mathrm{X}$, and (P) $\mathrm{SiX} 2$, where $\mathrm{R}=\mathrm{C} 6 \mathrm{H} 5$ or $\mathrm{CH} 3$ and $\mathrm{X}=\mathrm{OH}$ - or $\mathrm{ClO} 4$. Inorg. Chem. 1988, 27, 1191-1198.

(36) Gong, M.; Cao, Z.; Liu, W.; Nichols, E. M.; Smith, P. T.; Derrick, J. S.; Liu, Y.-S.; Liu, J.; Wen, X.; Chang, C. J. Supramolecular Porphyrin Cages Assembled at Molecular-Materials Interfaces for Electrocatalytic CO Reduction. ACS Cent. Sci. 2017, 3, 1032-1040.

(37) Pawlicki, A. A.; Vilan, A.; Jurow, M.; Drain, C. M.; Batteas, J. D. The Influence of Nearest-Neighbour Interactions and Assembly Dynamics on the Transport Properties of Porphyrin Supramolecular Assemblies on $\mathrm{Au}(111)$. Faraday Discuss. 2017, 204, 349-366.

(38) Lu, X.; Lv, B.; Xue, Z.; Li, M.; Zhang, L.; Kang, J. SelfAssembled Monolayers of a Thiol-Derivatized Porphyrin on Gold Electrode: Film formation and Electrocatalytic Dioxygen Reaction. Thin Solid Films 2005, 488, 230-235.

(39) Eriksson, K. L. E.; Chow, W. W. Y.; Puglia, C.; Backvall, J.-E.; Gothelid, E.; Oscarsson, S. Performance of a Biomimetic Oxidation Catalyst Immobilized on Silicon Wafers: Comparison with Its Gold Congener. Langmuir 2010, 26, 16349-16354.

(40) Vesper, B. J.; Salaita, K.; Zong, H.; Mirkin, C. A.; Barrett, A. G. M.; Hoffman, B. M. Surface-Bound Porphyrazines: Controlling Reduction Potentials of Self-Assembled Monolayers through Molecular Proximity/Orientation to a Metal Surface. J. Am. Chem. Soc. 2004, 126, 16653-16658.

(41) Xi, W.; Zhang, W.; An, B.-K.; Burn, P. L.; Davis, J. J. Tunnelling Conductance of Vectorial Porphyrin Monolayers. J. Mater. Chem. 2008, 18, 3109-3120.

(42) Uddin, S. M. N.; Nagao, Y. Multilayer Growth of PorphyrinBased Polyurea Thin Film Using Solution-Based Molecular Layer Deposition Technique. Langmuir 2017, 33, 12777-12784.

(43) Gadenne, V.; Portea, L.; Patrone, L. Structure and Growth Mechanism of Self-assembled Monolayers of Metal Protoporphyrins and Octacarboxylphthalocyanine on Silicon Dioxide. RSC Adv. 2014, 4, 64506-64513.

(44) Contino, A.; Maccarrone, G.; Fragal, M. E.; Spitaleri, v.; Gulino, A. Conjugated Gold-Porphyrin Monolayers Assembled on Inorganic Surfaces. Chem. - Eur. J. 2017, 23, 14937-14943.

(45) Lokesh, K. S.; Keersmaecker, M. D.; Adriaens, A. Self Assembled Films of Porphyrins with Amine Groups at Different Positions: Influence of Their Orientation on the Corrosion Inhibition and the Electrocatalytic Activity. Molecules 2012, 17, 7824-7842.

(46) Li, D.; Swanson, B. I.; Robinson, J. M.; Hoffbauer, M. A. Porphyrin based self-assembled monolayer thin films: Synthesis and characterization. J. Am. Chem. Soc. 1993, 115, 6975-6980.

(47) Li, D.; Buscher, C. T.; Swanson, B. I. Synthesis, characterization, and properties of covalently bound, self-assembled porphyrin multilayer thin films. Chem. Mater. 1994, 6, 803-810.

(48) Palomaki, P. K. B.; Krawicz, A.; Dinolfo, P. H. Thickness, Surface Morphology, and Optical Properties of Porphyrin Multilayer Thin Films Assembled on Si(100) Using Copper(I)-Catalyzed AzideAlkyne Cycloaddition. Langmuir 2011, 27, 4613-4622.

(49) Topka, M. R.; Dinolfo, P. H. Synthesis, Characterization, and Fluorescence Properties of Mixed Molecular Multilayer Films of BODIPY and Zn(II) Tetraphenylporphyrins. ACS Appl. Mater. Interfaces 2015, 7, 8053-8060.

(50) Kanaizuka, K.; Izumi, A.; Ishizaki, M.; Kon, H.; Togashi, T.; Miyake, R.; Ishida, T.; Tamura, R.; Haga, M.-a.; Moritani, Y.; Sakamoto, M.; Kurihara, M. Molecular nanostamp based on onedimensional porphyrin polymers. ACS Appl. Mater. Interfaces 2013, 5, $6879-6885$

(51) Kawaguchi, T.; Okamura, S.; Togashi, T.; Harada, W.; Hirahara, M.; Miyake, R.; Haga, M.-a.; Ishida, T.; Kurihara, M.; Kanaizuka, K. Potential tuning of nanoarchitectures based on phthalocyanine nanopillars: Construction of effective photocurrent generation systems. ACS Appl. Mater. Interfaces 2015, 7, 1909819103.

(52) Togashi, T.; Izumi, A.; Hiroki, K.; Katsuhiko, K.; Manabu, I.; Ryosuke, M.; Chang, H.-C.; Haga, M.-a.; Sakamoto, M.; Kurihara, M. Spontaneous construction of nanoneedles using ruthenium complexconjugated porphyrins on substrates. Chem. Lett. 2014, 43, 12011203.

(53) Kane, K. M.; Lorenz, C. R.; Heilman, D. M.; Lemke, F. R. Substituent Effects on the Spectroscopic Properties and Reactivity of Hexacoordinate Silicon(IV) Porphyrin Complexes. Inorg. Chem. 1998, 37, 669-673.

(54) Lee, D.-C.; Morales, G. M.; Lee, Y.; Yu, L. Cofacial porphyrin multilayers via layer-by-layer assembly. Chem. Commun. 2006, 1, $100-102$.

(55) Zheng, J.-Y.; Konishi, K.; Aida, T. Crystallographic Studies of Organosilicon Porphyrins: Stereoelectronic Effects of Axial Groups on the Nonplanarity of the Porphyrin Ring. Inorg. Chem. 1998, 37, 2591-2594.

(56) Kane, K. M.; Lemke, F. R.; Petersen, J. L. trans-Difluorosilicon(IV) Complexes of Tetra-p-tolylporphyrin and Tetrakis(p(trifluoromethyl)phenyl)porphyrin: Crystal Structures and Unprecedented Reactivity in Hexacoordinate Difluorosilanes. Inorg. Chem. 1997, 36, 1354-1359.

(57) Lu, L.; Lahasky, S. H.; Zhang, D.; Garno, J. C. Directed Growth of Polymer Nanorods Using Surface-Initiated Ring-Opening Polymerization of N-Allyl N-Carboxyanhydride. ACS Appl. Mater. Interfaces 2016, 8, 4014-4022.

(58) Youm, S. G.; Hwang, E.; Chavez, C. A.; Li, X.; Chatterjee, S.; Lusker, K. L.; Lu, L.; Strzalka, J.; Ankner, J. F.; Losovyj, Y.; Garno, J. C.; Nesterov, E. E. Polythiophene Thin Films by Surface-Initiated Polymerization: Mechanistic and Structural Studies. Chem. Mater. 2016, 28, 4787-4804.

(59) Daniels, S. L.; Ngunjiri, J. N.; Garno, J. C. Investigation of the magnetic properties of ferritin by AFM imaging with magnetic sample modulation. Anal. Bioanal. Chem. 2009, 394, 215-223.

(60) Li, J.-R.; Henry, G. C.; Garno, J. C. Fabrication of Nanopatterned Films of Bovine Serum Albumin and Staphylococcal 
Protein A Using Latex Particle Lithography. Analyst 2006, 131, 244250.

(61) Highland, Z. L.; Garno, J. C. Spatially selective binding of green fluorescent protein on designed organosilane nanopatterns prepared with particle lithography. Biointerphases 2017, 12, No. 02C402.

(62) Pi, F.; Dillard, P.; Limozin, L.; Charrier, A.; Sengupta, K. Nanometric Protein-Patch Arrays on Glass and Polydimethylsiloxane for Cell Adhesion Studies. ACS Nano 2013, 13, 3372-3378.

(63) Schlereth, A.; Noomuna, P.; Gao, P. Mesoscale Protein Patterning on a Self-Assembled Monolayer Coated Silicon Surface through Nanosphere Lithography. Acta Phys.-Chim. Sin. 2017, 33, $810-815$.

(64) Taylor, Z. R.; Keay, J. C.; Sanchez, E. S.; Johnson, M. B.; Schmidtke, D. W. Independently Controlling Protein Dot Size and Spacing in Particle Lithography. Langmuir 2012, 28, 9656-9663.

(65) Cai, Y.; Ocko, B. M. Large-Scale Fabrication of Protein Nanoarrays Based on Nanosphere Lithography. Langmuir 2005, 21, 9274-9279.

(66) Englade-Franklin, L. E.; Morrison, G.; Verberne-Sutton, S. D.; Francis, A. L.; Chan, J. Y.; Garno, J. C. Surface-Directed Synthesis of Erbium-Doped Yttrium Oxide Nanoparticles within Organosilane Zeptoliter Containers. ACS Appl. Mater. Interfaces 2014, 6, 1594215949.

(67) Mullen, T. J.; Zhang, M.; Feng, W.; El-khouri, R. J.; Sun, L.-D.; Yan, C.-H.; Patten, T. E.; Liu, G.-y. Fabrication and Characterization of Rare-Earth-Doped Nanostructures on Surfaces. ACS Nano 2011, 5, 6539-6545.

(68) Kulkarni, S. A.; Kolhatkar, A. G.; Lee, T. R.; Garno, J. C. Vibrational response of clusters of $\mathrm{Fe}_{3} \mathrm{O}_{4}$ nanoparticles patterned on glass surfaces investigated with magnetic sample modulation AFM. Nanoscale 2018, 10, 20426-20434.

(69) Lewandowski, B. R.; Kelley, A. T.; Singleton, R.; Li, J.-R.; Lowry, M.; Warner, I. M.; Garno, J. C. Nanostructures of CysteineCoated CdS Nanoparticles Produced with "Two-Particle" Lithography. J. Phys. Chem. C 2009, 113, 5933-5940.

(70) Fang, L.; Liu, X.; Xiang, S.; Liu, W.; Shen, H.; Li, Z.; Zhang, K.; Song, W.; Yang, B. Large-scale Au nanoparticle cluster arrays with tunable particle numbers evolved from colloidal lithography. Nanotechnology 2018, 29, No. 405301.

(71) Wang, Z.; Ai, B.; Möhwald, H.; Zhang, G. Colloidal Lithography Meets Plasmonic Nanochemistry. Adv. Opt. Mater. 2018, No. 1800402.

(72) Jensen, T. R.; Malinsky, M. D.; Haynes, C. L.; Van Duyne, R. P. Nanosphere Lithography: Tunable Localized Surface Plasmon Resonance Spectra of Silver Nanoparticles. J. Phys. Chem. B 2000, 104, 10549-10556.

(73) Haynes, C. L.; Van Duyne, R. P. Nanosphere Lithography: A Versatile Nanofabrication Tool for Studies of Size-Dependent Nanoparticle Optics. J. Phys. Chem. B 2001, 105, 5599-5611.

(74) Hulteen, J. C.; Treichel, D. A.; Smith, M. T.; Duval, M. L.; Jensen, T. R.; Van Duyne, R. P. Nanosphere Lithography: SizeTunable Silver Nanoparticle and Surface Cluster Arrays. J. Phys. Chem. B 1999, 103, 3854-3863.

(75) Pompa, P. P.; Martiradonna, L.; Della Torre, A.; Della Sala, F.; Manna, L.; De Vittorio, M.; Calabi, F.; Cingolani, R.; Rinaldi, R. Metal-enhanced fluorescence of colloidal nanocrystals with nanoscale control. Nat. Nanotechnol. 2006, 1, 126-130.

(76) Ferdele, S.; Jose, B.; Foster, R.; Keyes, T. E.; Rice, J. H. Strong coupling in porphyrin J-aggregate excitons and plasmons in nano-void arrays. Opt. Mater. 2017, 72, 680-684.

(77) Bae, C.; Shin, H.; Moon, J.; Sung, M. M. Contact Area Lithography (CAL): A New Approach to Direct Formation of Nanometric Chemical Patterns. Chem. Mater. 2006, 18, 1085-1088.

(78) Ishida, N.; Nishihara, R.; Imanaka, H.; Imamura, K. Nanostructures of 3-aminopropyltriethoxysilane created on flat substrate by combining colloid lithography and vapor deposition. Colloids Surf., A 2016, 495, 39-45.
(79) Brownfield, A. L.; Causey, C. P.; Mullen, T. J. Effects of surface water on organosilane nanostructure fabrication using particle lithography. Thin Solid Films 2015, 594, 184-191.

(80) Wang, S.; Sobczynski, D. J.; Jahanian, P.; Xhahysa, J.; Mao, G. A Supra-monolayer Nanopattern for Organic Nanoparticle Array Deposition. ACS Appl. Mater. Interfaces 2013, 5, 2699-2707.

(81) Zhai, X.; Lee, H. J.; Tian, T.; Lee, T. R.; Garno, J. C. Nanoscale Lithography Mediated by Surface Self-Assembly of 16-[3,5-Bis(Mercaptomethyl)phenoxy]hexadecanoic Acid on $\mathrm{Au}(111)$ Investigated by Scanning Probe Microscopy. Molecules 2014, 19, 1301013026.

(82) Sakurai, T.; Yoneda, S.; Sakaguchi, S.; Kato, K.; Takata, M.; Seki, S. Donor/Acceptor Segregated $\pi$-Stacking Arrays by Use of Shish- Kebab-Type Polymeric Backbones: Highly Conductive Discotic Blends of Phthalocyaninatopolysiloxanes and Perylenediimides. Macromolecules 2017, 50, 9265-9275.

(83) Giovannetti, R. The Use of Spectrophotometry UV-Vis for the Study of Porphyrins. In Macro to Nano Spectroscopy; Uddin, J., Ed.; Intech: Rijeka, Croatia, 2012; pp 87-108.

(84) Zhang, J.; Li, Y.; Zhang, X.; Yang, B. Colloidal Self-Assembly Meets Nanofabrication: From Two-Dimensional Colloidal Crystals to Nanostructure Arrays. Adv. Mater. 2010, 22, 4249-4269.

(85) Sun, F.; Yu, J. C.; Wang, X. Construction of Size-Controllable Hierarchical Nanoporous $\mathrm{TiO}_{2}$ Ring Arrays and Their Modifications. Chem. Mater. 2006, 18, 3774-3779.

(86) Chambers, P. C.; Garno, J. C. Heterostuctures of 4(chloromethyl)phenyltrichlorosilane and 5,10,15,20-tetra(4-pyridyl)$21 \mathrm{H}, 23 \mathrm{H}$-porphine prepared on $\mathrm{Si}(111)$ using particle lithography: Nanoscale characterization of the main steps of nanopatterning. Beilstein J. Nanotechnol. 2018, 9, 1211-1219.

(87) Ngunjiri, J. N.; Stark, D. J.; Tian, T.; Briggman, K. A.; Garno, J. C. Immobilization of proteins on carboxylic acid functionalized nanopatterns. Anal. Bioanal. Chem. 2013, 405, 1985-1993.

(88) Englade-Franklin, L. E.; Morrison, G.; Verberne-Sutton, S. D.; Francis, A. L.; Chan, J. Y.; Garno, J. C. Surface-directed synthesis of Erbium-doped Yttrium oxide nanoparticles within organosilane zeptoliter containers. ACS Appl. Mater. Interfaces 2014, 6, 1594215949.

(89) Zhai, X.; Arachchige, N. M. K. K.; Derosa, P.; Garno, J. C. Conductive-probe measurements with nanodots of free-base and metallated porphyrins. J. Colloid Interface Sci. 2017, 486, 38-45.

(90) Druzhinina, T. S.; Höppener, C.; Hoeppener, S.; Schubert, U. S. Hierarchical, Guided Self-Assembly of Preselected Carbon Nanotubes for the Controlled Fabrication of CNT Structures by Electrooxidative Nanolithography. Langmuir 2013, 29, 7515-7520.

(91) Chowdhury, D.; Maoz, R.; Sagiv, J. Wetting Driven SelfAssembly as a New Approach to Template-Guided Fabrication of Metal Nanopatterns. Nano Lett. 2007, 7, 1770-1778.

(92) Zeira, A.; Berson, J.; Feldman, I.; Maoz, R.; Sagiv, J. A Bipolar Electrochemical Approach to Constructive Lithography: Metal/ Monolayer Patterns via Consecutive Site-Defined Oxidation and Reduction. Langmuir 2011, 27, 8562-8575.

(93) Eissa, M. M.; Rahman, M. M.; Zine, N.; Jaffrezic, N.; Errachid, A.; Fessi, H.; Elaissari, A. Reactive magnetic poly(divinylbenzene-coglycidyl methacrylate) colloidal particles for specific antigen detection using microcontact printing technique. Acta Biomater. 2013, 9, 55735582.

(94) Fang, J.; Knobler, C. M. Phase-Separated Two-Component Self-Assembled Organosilane Monolayers and Their Use in Selective Adsorption of a Protein. Langmuir 1996, 12, 1368.

(95) Li, J.-R.; Lusker, K. L.; Yu, J.-J.; Garno, J. C. Engineering the spatial selectivity of surfaces at the nanoscale using particle lithography combined with vapor deposition of organosilanes. ACS Nano 2009, 3, 2023-2035.

(96) Saner, C. K.; Lusker, K. L.; LeJeune, Z. M.; Serem, W. K.; Garno, J. C. Self-assembly of octadecyltrichlorosilane: Surface structures formed using different protocols of particle lithography. Beilstein J. Nanotechnol. 2012, 3, 114-122. 
(97) Li, J. R.; Garno, J. C. Elucidating the role of surface hydrolysis in preparing organosilane nanostructures via particle lithography. Nano Lett. 2008, 8, 1916-1922.

(98) Li, J. R.; Lusker, K. L.; Yu, J. J.; Garno, J. C. Engineering the Spatial Selectivity of Surfaces at the Nanoscale Using Particle Lithography Combined with Vapor Deposition of Organosilanes. ACS Nano 2009, 3, 2023-2035.

(99) Nečas, D.; Klapetek, P. Gwyddion: an open-source software for SPM data analysis. Cent. Eur. J. Phys. 2012, 10, 181-188. 